\title{
Territorio y municipio. El tema en la provincia de Buenos Aires
}

\author{
Pablo Reca \\ Profesor de Derecho Administrativo \\ Universidad de La Plata (Argentina)
}

Sumario: 1. EL MARCO MUNICIPAL. 1.1. Una visión jurídica constitucional. 1.2. El tema en la Provincia de Buenos Aires. 2. TERRITORIO Y MUNICIPIO. 2.1. La Base Territorial. 2.2. La Intangibilidad Territorial. 2.3. El Planeamiento Territorial. 2.4. El Ordenamiento Territorial. 3. A MODO DE COROLARIO.

\section{EL MARCO MUNICIPAL}

Es copiosa la literatura jurídica que alude en la última década a la autonomía municipal ${ }^{1}$ y muy especialmente a la cuestión institucional como aptitud inherente a sus atribuciones ${ }^{2}$.

Más que un aporte teórico o de actualización doctrinaria, los escritos reflejan una vasta corriente de pensamiento consistente en reconocer al gobierno local, como el último estadio competencial de nuestra organización federal ${ }^{3}$; zanjando una cuestión que merecía, hasta no hace tanto, significativas reservas en nuestra doctrina ${ }^{4}$.

1 «...Las Provincias deberán revisar sus Constituciones para adaptarlas a las nuevas pautas establecidas en la Constitución federal...». S.A. SABSAY, y J.M. OnAINDIA, (1998). La Constitución de los Argentinos, pág. 404. Argentina: Errepar. «...Las leyes supremas provinciales deben obligatoriamente adecuarse al art. 123 de la Constitución Nacional y en el actual régimen municipal argentino, hay que reformar las constituciones de Buenos Aires, Entre Ríos, Mendoza, Santa Fe y Tucumán, porque ya hemos visto que no aseguran la autonomía local de dicha manera, especialmente en el orden institucional...», A.M. Hernández, «Municipio, Coordinación Municipal y Desarrollo Sustentable». Documento base elaborado para el $2^{\circ}$ Coloquio FARN. Propuestas de Políticas Públicas para el Desarrollo Sustentable. Junio 1999. Villa Carlos Paz, Córdoba. Pág. 139.

${ }^{2}$ Luis ORTEGA expresa: «...La autonomía comprende la «potestad de libre decisión en el ejercicio de sus competencias» o bien significa «autodeterminación», determinación libre en cuanto a la actuación, dentro del marco del ordenamiento jurídico». Por ello, es aplicable al concepto constitucional de autonomía las elaboraciones de la doctrina alemana sobre la Selbstverwaltung en el sentido de autorresponsabilidad en el ejercicio de la competencia que implica «la necesidad de un poder de libre determinación no sometido a otros controles que no sean los de legalidad, sin sometimiento a directivas o instrucciones estatales...». El Régimen Constitucional de las Competencias Locales, Ed. Instituto Nacional de Administración Pública, Madrid 1988, pag. 25.

3 «...En última instancia, el mantenimiento del federalismo implica la «mentalidad federal», es decir, la orientación del pensamiento hacia los ideales y normas del republicanismo, el constitu- 


\subsection{Una visión jurídica constitucional}

Sin duda el mandato explícito de la Constitución Nacional y la evolución del Derecho Público provincial sobre la materia, han conformado una malla sólida que nos ubica definitivamente en una dimensión trijurisdiccional y con ello en una insinuante reparación socio-histórica de nuestra forma de Estado $^{5}$, como fundamento mismo del poder político ${ }^{6}$.

cionalismo y la distribución del poder, que son elementos esenciales para la vía federal... No hay ningún sistema federal que haya alcanzado el éxito — según los cánones del federalismo- y que no posea una mentalidad y una cultura política federales, unidas a una firme voluntad de aplicar principios y disposiciones federales...». Daniel J. Elazar, Exploración del Federalismo. Ed. Hacer, Barcelona, 1991, pág. 241.

${ }^{4}$ Sobre este tipo de reparos expresaba Agustín GoRDILLO «...No existe una propuesta generalizada entre los autores de derecho constitucional y administrativo de trasladar alguna de estas ideas de «autonomía» municipal, o «cartas» municipales, a nivel de exigencia de la Constitución Nacional para que todas las provincias se ajusten luego a ella. Este tipo de propuestas quedan por lo general limitadas a reuniones y a autores de neto corte municipalista, sin lograr generar consenso y adhesión en el resto de la doctrina publicista. Por lo demás es claro que la Constitución Nacional, que pudiera haber sido objeto de una interpretación amplia y generosa, fue entendida en el más sentido literal de requerir un régimen, cualquiera, municipal». Trabajo presentado al «Congreso Iberoamericano de Profesores de Derecho Administrativo», Madrid, 23 al 28 de mayo de 1983, sobre el tema «Situación actual y Perspectivas de la Administración Local», organizado por el Instituto de Estudios de Administración Local, incorporado al libro: Temas de Derecho Municipal, pensamiento Jurídico Editora, Bs. As. 1991, pág. 132.

${ }^{5}$ Hace 150 años Juan Bautista AlbeRdi precisaba: «... De un antiguo Cabildo español había salido a luz, el 25 de mayo de 1810, el gobierno republicano de los argentinos; pero a los pocos años este gobierno devoró al autor de su existencia. El parricidio fue castigado con la pena del talión, pues la libertad republicana pereció a manos del despotismo político, restaurado sin el contrapeso que antes le oponía la libertad municipal.

Entonces la República Argentina, inundada de gobernadores omnipotentes, presentó el cuadro de los pueblos europeos del siglo XI, en que los grandes señores feudales eran los árbitros pesados de las ciudades. Por muchos años ha durado ese estado de cosas, contra el cual están hoy por constituir garantías los pueblos de la República Argentina, trabajados por la anarquía y el despotismo.

La más poderosa de que puedan echar mano es la organización municipal. Ella debe ser base de la organización de la provincia y alma del nuevo orden general de cosas. Por ella han dado principio a su emancipación todos los pueblos que se han visto en situación parecida a la que hoy tienen los pueblos argentinos. Por él dio principio la formación del pueblo romano: por él, comenzó la organización de los pueblos de Estados Unidos; y los pueblos de Europa, al salir de la Edad Media, empezaron también su vida regular por la organización del sistema de los comunes o cuerpos municipales...». «Derecho Público Provincial Argentino». Ed. Ciudad Argentina, Buenos Aires, 1998, pág. 55.

${ }^{6}$ «... Georges BURDEAU, advertía la frecuencia con que equivocadamente se involucra la forma de Estado y la de su Gobierno, sin tener en cuenta que la primera se refiere al fundamento mismo del poder político, mientras la forma de gobierno «está determinada por la manera en que son designados los agentes que ejercen ese poder y el modo de realizarlo. De allí se explica -aún cuando la forma de Estado influye en una cierta medida sobre la de su Gobierno- que Estados de forma semejante sean regidos por procedimientos gubernamentales diferentes, e inversamente, formas de gobiernos semejantes pueden existir en Estados de estructuras diferentes»...», citado por Luis 
Poco o nada se discute ya sobre el genérico concepto del artículo 123 cuando reza: «Cada provincia dicta su propia constitución, conforme a lo dispuesto por el artículo 5 asegurando la autonomía municipal y reglando su alcance y contenido en el orden institucional, político, administrativo, económico y financiero», enunciado que debe interpretarse como el alcance de una facultad, que en nada puede desvirtuar la naturaleza del ente que la posee, como condición inalienable de su propia existencia ${ }^{7}$.

\subsection{El tema en la Provincia de Buenos Aires}

Sin embargo, resulta una cita común señalar que la provincia de Buenos Aires ha desconocido este explícito mandato ${ }^{8}$, generando una sórdida e impávida controversia, cuyo efecto más insurgente es el haber cercenado la aptitud decisional local ${ }^{9}$ — comenzando por su competencia constituyenteprovocando un cautiverio legislativo que acentúa una marcada involución ${ }^{10}$.

1.2.1. Las razones políticas que llevaron a tamaña omisión en la Convención Constituyente Bonaerense del año 1994 han sido variadas y nunca

Villar Borda, Democracia Municipal, Autonomía, Planificación y Desarrollo. Ed. Universidad Externado de Colombia, Bogotá, 1986, pág. 139.

${ }^{7}$ «...La organización técnica del federalismo es, un problema extremadamente delicado. Al constituyente se presenta la tarea de saber encontrar el término medio entre la exigencia de tutelar y preservar las autonomías que conviven en el ordenamiento federal y la de favorecer las oportunas modificaciones del mismo. Sólo de esta forma se puede desenvolver el sistema federal, es decir, constituir un proceso y mantener, al mismo tiempo, íntegras sus propias características estructurales...». Antonio La Pergola, Los Nuevos senderos del Federalismo, Ed. Centro de Estudios Constitucionales, Madrid, 1994, pág. 24.

${ }^{8}$ Humberto Quiroga Lavié señala: «...También queremos destacar que esta reforma de la Constitución de la Provincia de Buenos Aires no fue la amplia y sistematizada como lo fuera la que, desgraciadamente, quedara en el camino luego del plebiscito negativo de 1990. Muy especialmente se debe deplorar la oportunidad perdida por la provincia para afirmar la autonomía de los municipios existentes en ella, sobre todo frente a la clara norma que en tal sentido venía impulsando el art. 123 de la nueva Constitución Nacional... de modo tal que si Buenos Aires no ha escuchado la indicación nacional en tal sentido, la autonomía municipal ha quedado, obviamente, perjudicada...». Constitución de la Provincia de Buenos Aires, ED. Rubinzal - Culzoni, 1995, pag. 10.

${ }^{9}$ Jorge VANOSSI nos recuerda: «... El quehacer político por antonomasia es la decisión o, mejor dicho, tomar decisión. De allí que un sistema constitucional dado será tanto más valioso cuanto más «decidida» las cuestiones fundamentales de la organización política de un Estado o cuanto mejor establezca los procedimientos destinados a que ciertos órganos tomen esas decisiones...». Teoría Constitucional, Ed. Depalma, segunda edición actualizada, año 2000, pág. 40.

${ }^{10}$ Sobre el tema nos hemos referido en el trabajo: La crisis municipal en la Provincia de Buenos Aires, Actualidad del Derecho Administrativo en la Provincia de Buenos Aires, editado por Función Pública, año 1998 pág. 41 y ss. 
suficientemente aclaradas ${ }^{11}$, el abandono del despacho en mayoría ${ }^{12}$ encontró su justificación en la promesa de una actualización no cumplida y en posteriores y erráticos ensayos de «descentralización» ${ }^{13}$ que relativizando su alcance organizacional ${ }^{14}$ y bajo el apotegma de la eficiencia ${ }^{15}$,

\footnotetext{
${ }^{11}$ Es indudable que la falta de reforma del capítulo municipal —oportunamente habilitada por la Ley 11.488 - tuvo como eje no explícito el conflicto suscitado por el Reglamento de la Convención y la judicialización de la cláusula que incorporaba la reelección del gobernador. Sobre la cuestión nos hemos referido ampliamente en el Semanario de la Reforma Bonaerense: El Constituyente, editado por Producciones Sol S.R.L., año 1994.
}

${ }^{12}$ Sobre el estudio que nos ocupa, el Despacho en mayoría preveía lo siguiente: «El gobierno y administración de los asuntos locales, en la Capital y en el resto de la Provincia estarán a cargo de las Municipalidades, cuyas funciones políticas y administrativas y modalidades de gestión, ejercerán sin sujeción a otro poder, conforme a la presente Constitución y a las leyes que en su consecuencia se dicten.

Competencias.

10. Elaborar, aprobar, y ejecutar planes generales o sectoriales de desarrollo urbano y rural.

11. Regular el uso del suelo y la organización territorial de cada partido, de acuerdo a los lineamientos generales establecidos por la Ley provincial...

13. Promover, proteger, y preservar el patrimonio histórico, cultural, arquitectónico y artístico de las ciudades y los pueblos rurales, estableciendo limitaciones, servidumbres y restricciones razonables a la propiedad por motivos de interés público, de acuerdo a esta Constitución y a las leyes.

14. Disponer medidas de regulación, policía, manejo y conservación del medio ambiente con arreglo a la presente Constitución y a la Ley.

15. Crear órganos y entes descentralizados institucionales, regionales, o intermunicipales, a los fines de la presentación de servicios públicos, la ejecución de obras, la asistencia financiera, la cooperación técnica, la realización de planes de desarrollo y de todo otro emprendimiento de utilidad común...». Revista de la Honorable Convención Constituyente de la Provincia de Buenos Aires. $11^{\circ}$ sesión, Despacho en mayoría de la Comisión de Poderes, Interpretación, Reglamento, Redacción y Coordinación General. Septiembre 6 de 1994.

${ }^{13}$ Antonio La Pergola enfatiza: «...Hay un peligroso error de perspectiva consistente en reducir, sin residuos, a un mismo paradigma estructural las formas de descentralización por muy avanzadas que sean, y aquellas otras en que se concreta el federalismo de origen convencional. Dado que se trata de dos procesos diferentes, hay razones para suponer que no se puedan desenvolver con las mismas e idénticas modalidades..., ob. cit., pág. 67.

${ }^{14}$ Considerando nuestras prioridades institucionales —en especial en la provincia de Buenos Aires - no compartimos la perspectiva y el gradualismo que sostiene parte de la doctrina al señalar: «...El viejo e importante debate sobre autonomía política o administrativa y sobre descentralización o desconcentración no puede hoy plantearse en términos antagónicos. El proceso descentralizador contiene elementos de simple desconcentración administrativa que son, sin embargo, avances importantes y necesarios que posibilitan ulteriores progresos de la descentralización política. Por ejemplo, la organización territorial de los servicios, la delegación de la gestión aunque no se transfiera la competencia o la atribución de funciones de iniciativa o de colaboración, pueden sentar las bases de la descentralización...». Jordi Borja, Organización y descentralización municipal, Ed, Eudeba, año 1987, pág. 19.

${ }^{15}$ Estamos de acuerdo con Jean DE SAVIGNY cuando expresa: «...Es, pues, forzoso admitir que el pretexto de la eficacia, esgrimido a veces en Francia para contestar la legitimidad de la autonomía local, no es más que una manifestación, puesta al estilo del momento, de nuestro atavismo centra- 
no han hecho más que profundizar las falencias estructurales que presenta el Municipio de nuestra Provincia.

1.2.2. La situación descripta lleva a preguntarnos si hay una conciencia del territorio; ponderado desde la doble óptica de crear riqueza sobre él (como reflejo de una obra eminentemente social o colectiva), y como inalienable competencia municipal que permita proveer con claridad su ejercicio jurisdiccional.

\section{TERRITORIO Y MUNICIPIO}

Si en la actualidad el reconocimiento del gobierno local, presume su naturaleza sociológica ${ }^{16}$ y aptitud autonómica, debemos extender este alcance a los paramentos constitutivos que le dan razón de ser.

El territorio representa la base de sustentación física que delimita el alcance de las competencias locales y el sentido de su configuración, donde se asienta y justifica su gobierno.

Cuatro aspectos nos interesa considerar:

\subsection{La base territorial}

Es indudable que esta atribución es de naturaleza Provincial, atendiendo a la facultad que le asiste a la Legislatura para trazar las divisiones territoriales ${ }^{17}$.

lizador... La descentralización del poder no conduce por sí misma a las libertades locales: éstas no se expresan sólo por la existencia de poderes locales, sino por la de poderes locales autónomos, es decir, responsables no ante el Estado, sino ante los ciudadanos locales». ¿El Estado contra los Municipios?, Ed. Inst. de Estudios de Administración Local, Madrid, 1978.

${ }^{16}$ Antonio HernÁNDEZ subraya que: «...La naturaleza sociológica del municipio. Es el primer principio establecido por las constituciones, tal como surge de la cordobesa, que en su art. 180 dice: «Esta Constitución reconoce al existencia del municipio como una comunidad natural fundada en la convivencia»; la jujeña, que en su art. 178 expresa: «...la autonomía necesaria para resolver los asuntos de interés local a los fines del libre y mejor desarrollo de la comunidad»; la sanluiseña, que en su art. 247 prescribe: «Esta Constitución reconoce al municipio como una comunidad natural con vida propia e intereses específicos, con necesarias relaciones de vecindad...». FríAs y otros, Las Nuevas Constituciones Provinciales. Ed. Depalma, Bs. As., 1989, pág. 210.

17 Art. 103 inc. 4 de la Constitución Provincial «...fijar las divisiones territoriales para una mejor administración...».

Debemos señalar que esta potestad legislativa, no se la debe confundir con la aptitud de «crear municipios» que es un reconocimiento que debe ser garantizado constitucionalmente, como lo demuestran la mayoría de las Cartas Estaduales. 
Para nosotros los modelos aplicables (municipio-ciudad; municipiodistrito; municipio-partido) presentan límites no suficientemente claros ${ }^{18}$, y requieren más que el dogmatismo de las categorizaciones, una creatividad jurídica que reconozca los distintos asentamientos poblacionales, evitando provocar una exagerada «atomización», o una forma de «concentración» que desvirtúe el sentido de identidad y pertenencia que define la interacción social con su ámbito.

En este sentido creemos que el mejor criterio lo constituye la posibilidad de la individualización municipal ${ }^{19}$, es decir, límites que traduzcan una realidad morfológica, urbanística, demográfica y cultural con una aptitud económica-financiera que posibilite su desarrollo autónomo. Ello sin perjuicio que la Constitución reconozca otros Entes locales menores y que el municipio cuente con la potestad de promover la descentralización funcional y/o política que mejor refleje su complejidad distrital.

\subsection{La intangibilidad territorial}

Le damos una especial significación al tema porque para nosotros asumir la responsabilidad primaria por parte del municipio en el ordenamiento territorial, requiere imprescindiblemente reivindicar el propio territorio, es decir, el reconocimiento a su configuración espacial-jurisdiccional. En consecuencia, concebimos el territorio como un elemento integrante e intangible del municipio, que sólo podrá ser susceptible de un potencial desmembramiento, cuando se reúnan las condiciones constitucionales o legislativas para el reconocimiento en su ámbito de un nuevo municipio.

Desde ya, otra cuestión será la voluntad de los municipios para modificar sus límites territoriales (fusión, división, cesión), la que deberá llevarse a cabo bajo un marco básico regulatorio, que plasme un claro procedimiento garantizando —entre otros tópicos - las instancias consultivas necesarias ${ }^{20}$.

\footnotetext{
18 «...Los límites territoriales han sido las coordenadas que han regido históricamente el ámbito de acción de las administraciones locales. Dicha tendencia se ha ido transformando con los procesos de urbanización y el crecimiento de asentamientos humanos espontáneos que rebasan los espacios territoriales...». Jorge WiTKER, La Administración Local en México. Ed. Instituto de Estudios de Administración Local, Madrid, 1986, pág. 159.

${ }^{19}$ Capítulo aparte merecen los municipios involucrados en las áreas metropolitanas, cuya «unidad funcional» exige otro tipo de criterios organizativos. Sobre la cuestión nos hemos referido en el libro de Derecho Urbanístico, editorial La Ley, año 2002.

${ }^{20}$ Rechazamos con énfasis la forma en que se ha llevado a cabo la cesión y fusión de distintos municipios del área metropolitana durante los años 1994 y 1995. Sobre el tema nos hemos referi-
} 


\subsection{El planeamiento territorial}

Además de lo aludido, resulta necesario subrayar que el planeamiento urbano local para que alcance un nivel de implementación eficaz y progresivo, requiere de otras dos condiciones que derivan sustantivas para su efectiva operatividad.

2.3.1. Nos referimos a un marco de ordenamiento territorial que asuma una perspectiva que conjugue las diferentes fenómenos con incidencia y actuación sobre el territorio.

Sin este marco — que la Constitución en novedosa incorporación faculta ${ }^{21}$-, no lograremos implementar la coordinación y jerarquía de los planes que exige esta concepción, así como la distribución y asignación de las respectivas competencias 22 .

Por cierto, ello no es adscribir a una posición totalizadora, que suponga desmerecer los esfuerzos locales o provinciales que hayan tenido lugar o las honrosas excepciones donde han concurrido una férrea voluntad política con una análisis técnico, referencias que reflejan un significativo precedente en la materia ${ }^{23}$.

do ampliamente en el trabajo «La Creación de los municipios en la provincia de Buenos Aires», en la Revista Argentina del Régimen de la Administración Pública, Editorial Ciencias de la Administración División Estudios Administrativos, año 1999, n 247 y 248.

${ }^{21}$ Art. 41 de la Constitución Nacional: «Todos los habitantes gozan del derecho a un ambiente sano... Las autoridades proveerán la protección de este derecho, a la utilización racional de los recursos naturales, a la preservación del patrimonio natural y cultural y de la diversidad biológica, y la información y educación ambientales.

Corresponde a la Nación dictar las normas que contengan los presupuestos mínimos de protección, $\mathrm{y}$ a las provincias, las necesarias para complementarlas, sin que aquellas alteren las jurisdicciones locales...».

$22 \ll \ldots$ Lo importante es que todo el planeamiento se sujeta a un principio de jerarquía, en cuya virtud los planes de ámbito superior contienen una serie de determinaciones a las que han de ajustarse los planes de nivel territorial más limitado. De este modo, la planificación municipal y, más ampliamente, las facultades «de índole local», han de atenerse a los criterios y a las determinaciones expresas de la planificación de nivel territorial superior...» Eduardo GarCía DE ENTERRÍA, Derecho Administrativo. Tomo II. Facultad de Derecho. Universidad Complutense de Madrid. Madrid, 1978-1979, pag. 63.

23 «...La década de los cuarenta marcó también la euforia de los planes reguladores que desfogaron a los antiguos proyectistas de centros cívicos y renovaciones urbanas por todo el país. Los anteproyectos para la reconstrucción de San Juan, luego del terremoto de 1944, pusieron en evidencia la oferta de modelos desde la ciudad jardín, a las supermanzanas del urbanismo moderno $\mathrm{y}$, finalmente, a la razonabilidad de mantener lo preexistente frente a la aventura de la ciudad $e x$ novo. Los concursos para los planes de Rosario (1928) y de Mendoza (1940), o el del ingeniero Benito Carrasco en Córdoba (1927), marcaron hitos en el desarrollo de la nueva ciencia urbanís- 
Se trata de un requisito que recoja y plasme las asimetrías territoriales, demográficas, económicas y culturales que ofrece el país; en una palabra, una imprescindible oportunidad para afianzar el federalismo ${ }^{24}$ y plasmar una visión de conjunto en la diversidad ${ }^{25}$.

2.3.2. El otro punto sustancial es - como ya dijimos- el reconocimiento pleno y efectivo de la autonomía municipal. Desde esta posición las competencias otorgadas en el campo del planeamiento urbanístico, van a superar la mera concepción física y edilicia ${ }^{26}$, para incorporarse en una dimensión que traduzca la acción sobre el territorio todo, ajustando su cometido a las particularidades e idiosincrasia de su ámbito.

2.3.2.1. Suele plantearse que esta idea presume una actitud centralizadora, o en otros términos que la organización que exige el urbanismo y la autonomía municipal colisionan en una inevitable tensión de intereses.

Resulta esta una falsa antinomia, que dispersa en corrientes y reivindicaciones, la natural concurrencia de objetivos que requiere la materia.

Corresponde señalar con vigor, que si bien la autonomía resulta indispensable — porque en ella descansa el ámbito de decisión propio ${ }^{27}$-, ésta

tica...». Ramón Gutiérrez. La Ciudad y sus Transformaciones. Ed. Planeta, Buenos Aires, 2001, pág. 184.

24 «...Es hoy una certidumbre adquirida, además de una experiencia general, la vieja verdad expuesta hace ya más de cien años por Rudolf Gneist y reiterada hace cincuenta en un trabajo clásico sobre el Estado de Derecho del suizo Dietrich Schindler según la cual «no es casual que el sistema de un Estado de Derecho esté vinculado normalmente con el de un Estado federal, pues, en efecto, la idea esencial de un sistema federal es la misma que la del Estado de Derecho, la formación de una unidad en la diversidad; dentro del Estado de Derecho se trata de una unión por encima de las diferencias sociales o estructurales, en el Estado federal de unir divisiones territoriales...». José Luis GonZález-Berenguer y Urrutia, La Ley del Suelo. Ed. Civitas, Madrid, 1997, pág. 38.

25 «...Sin multiplicidad, sin independencia, no hay vida, no hay espontaneidad, no hay libre desarrollo en las poblaciones. Multitud - ha dicho Pascal- que no se reduce a la unidad, es confusión; unidad que no depende de la multitud, es tiranía. Juan Bautista AlberdI, ob. cit., pág 33.

26 «...La Ley de Propiedad Horizontal en 1948 abrió nuevas posibilidades y fomentó la construcción en altura, sin un adecuado control de los municipios, generalmente débiles frente a la presión de la inversión económica y, a menudo, carentes de estrategias e ideas propias para la ciudad. Los códigos de edificación eran permisivos y la política de excepciones mostraría en reiteradas oportunidades la fragilidad de un poder público que no ejercía la tutela del bien común urbano...». Ramón GuTIÉRREZ, ob. cit., pág. 190.

27 «...El desarrollo de una nueva perspectiva de análisis político, centra su atención en la observación y estudio de los procesos de decisión y que conjuga un doble interés que a veces se encuentra separado en el desarrollo del pensamiento político, a saber, el de la teoría política empírica por una parte y el de la teoría política normativa por la otra. La perspectiva de la toma de decisiones 
no merma al traducir en el campo que nos ocupa, una competencia residual que debe desarrollarse en el contexto de la ley marco y las leyes sectoriales que contemplan la distribución de competencias en la acción de la trama urbana ${ }^{28}$.

Tampoco habrá menoscabo alguno en reconocer que una determinada realidad local exceda su órbita y alcance un status «supralocal» ${ }^{29}$, ya que lejos de conmover las competencias propias, tal reconocimiento las confirma ${ }^{30}$.

\subsection{El ordenamiento territorial}

Entendemos esta disciplina como el conjunto de normas que regulan la actividad de ordenación del uso del suelo y, en consecuencia la gestión,

conjuga esta doble dimensión...». Leandro Area. Los Procesos de Decisión Política. Editorial Jurídica Venezolana, Caracas, 1983, pág. 13.

${ }^{28}$ Con claridad nos recuerda García de EnTERRía «...Y Ya se va haciendo ostensible en el entorno intelectual y práctico del urbanismo la existencia de dos círculos de problemas de muy diferente radio de acción. Aunque las expresiones sean harto convencionales, enseguida se pudo comprobar que hay dos marcos de referencia: el primero, atento a la concreta realidad de cada trama urbana; el segundo pendiente de acondicionar espacios más grandes, tiende a desembocar en lo que se ha venido denominando ordenación del territorio.

En la reforma de 1975, este doble nivel de urbanismo se expresa ya de un modo patente en los distintos niveles territoriales del planeamiento: por una parte los Planes Directores Territoriales de Coordinación están concebidos como instrumento de ordenación de espacios de carácter regional $\mathrm{y}$, por otra, se mantienen los planes de nivel municipal.

El Texto refundido de la Ley del Suelo, en su artículo 214, establece que «la competencia urbanística de los Ayuntamientos comprenderá todas las facultades que siendo de índole local no hubiesen sido expresamente atribuidas por la presente Ley a otros Organismos».

La concepción de la Ley es, pues, la de otorgar al Municipio una competencia residual, en la medida en que el propio legislador no haya atribuido de modo expreso competencias concretas a las demás instituciones que contempla. Para apreciar el contenido real de las funciones urbanísticas municipales hay que medir el sentido del precepto en el contexto de la propia Ley del Suelo, de la Ley de Régimen Local y de las Leyes y ordenaciones sectoriales que contemplan la distribución de competencias concretas en cada uno de los servicios que requiere la trama urbana...». Ob. cit., pág. 63

${ }^{29}$ En el proyecto de reforma plebiscitado en el año 1990 en el art. 185 in fine se preveía: «....Igualmente, podrán constituir entre sí, o entre sí y con la provincia, organismos de Gobierno o planeamiento regional cuya creación deberá ser aprobada por ley. La ley dispondrá el origen de los recursos y la atribución de competencias a favor del nuevo organismo, las que posteriormente no podrán ser ejercidas por los municipios que lo integren...».

30 «...La reclamación de la competencia exclusiva del Municipio en todos los asuntos de la comunidad local comporta la necesaria contrapartida de la restricción o limitación estricta del autogobierno municipal a dichos asuntos. De ahí que deba entenderse que la adquisición por un asunto hasta entonces gestionado por la Administración municipal de una lógica o un interés supralocal 
ejecución y control de los procesos de transformación de este recurso encaminados a su utilización ${ }^{31}$.

Implica una indudable competencia nacional, ya que comprende entre otros aspectos:

- las políticas que determinan cómo, cuándo y dónde deben surgir y desarrollarse los asentamientos humanos y los instrumentos técnicos precisos para lograr tales objetivos;

- los principios rectores del urbanismo que deben informar la práctica judicial y la actuación de los poderes públicos;

— el orden de distribución de competencias entre los poderes públicos nacional, provincial y local.

2.4.1. Cualquier planteo normativo que se haga al efecto debe contemplar el problema de nuestra estructura urbana ${ }^{32}$, ya que de esta visión

provoca sin más y de suyo el desplazamiento de la competencia para su gestión, toda vez que dicho asunto deja en dicho momento de poseer la cualidad necesaria para su inclusión en el ámbito de competencia propio de aquella Administración. Por lo mismo, la disposición legal que reasigne a una instancia territorial superior la competencia sobre la materia que haya experimentado una transformación de las indicadas características, no estará alterando constitutivamente el cuadro de competencias existente (ni, por tanto, incidiendo en la autonomía local), sino limitándose a recoger o trasladar formalmente al plano de la legalidad un hecho que ya ha tenido lugar...». Luciano Parejo Alfonso. Garantía Institucional y Autonomías Locales. Instituto de Estudios de Administración Local, Madrid, 1981, pág. 78.

${ }^{31}$ Concebido con esta amplitud, existe una acusada interrelación entre la ordenación territorial y la actividad urbanística. En el caso de la actividad urbanística, se trata de definir las concretas actividades que sobre el suelo pueden materializarse. En el de ordenación del territorio, se trata de definir el marco general en el que la actividad urbanística deba tener lugar. De otro lado, actividad y ordenación dan a entender que la función de gobierno enmarca necesariamente la actividad urbanística y establece las opciones básicas a que debe atenerse su gestión. Manuel Medina de Lemus. Derecho Urbanístico. J. M. Bosch Editor, Zaragoza, 1999, pág. 13.

${ }^{32} \mathrm{La}$ estructura urbana argentina nos presenta un cuadro atípico: una gran ciudad y su conurbano con más de 10.000.000 de habitantes, lo cual representa el 35\% de la población del país; tres ciudades con más de un millón de habitantes y su periferia urbana (Rosario, Córdoba, Mendoza) que representan el $12 \%$ de la población nacional, y quince ciudades con más de 100.000 y hasta 500.000 habitantes que representan el $13 \%$ de la población. He aquí el $60 \%$ de la población.

El resto lo componen veinticuatro ciudades: 50.000 a 100.000 hab. (8\%); sesenta y cinco ciudades: 20.000 a 50.000 hab. (7\%); ciento cinco ciudades 10.000 a 20.000 hab. (6\%); ciento ochenta ciudades: 5.000 a 10.000 hab. (4\%) y cuatrocientos cincuenta pueblos: 1.000 a 2.000 habitantes (3\%) y el remanente del $9 \%$ de la población se encuentra atomizado en pequeñas villas y organizaciones de vida típicamente rural.

Este panorama no ha variado demasiado, según el último censo del 2001, el total de población urbana en todo el país es de 36.223.947, considerándose población urbana la censada en localidades que cuenten con 20.000 o más habitantes. 
dependerán las distintas políticas (vgr. vivienda, infraestructura, etc.) que induzcan a una distribución poblacional más equitativa.

Esta ley-marco también debe considerar una relación estructural con el medio ambiente que sistematice ambas disciplinas. Gran parte de las disfuncionalidades públicas que tenemos en este campo, se deben a una desconexión histórica entre ambos fenómenos que desplazan su compresión jurídica ${ }^{33}$. Desde esta óptica, deberá incorporarse el tema de la «preservación del patrimonio cultural $^{34}$ » porque constituye nuestro más imperecedero e invalorable aporte civilizador y sintetiza los criterios de nuestra identidad urbana ${ }^{35}$.

Asimismo, deberá reconocer las regiones que presenta el país, como expresión de afinidades que reflejan claramente sus diversas características y necesidades. En este sentido merece una perentoria atención el Área Metropolitana de Buenos Aries ${ }^{36}$.

La región metropolitana (Capital Federal y veinticuatro partidos del Gran Buenos Aires) cuenta con 2.768 .772 y 8.684 .953 respectivamente de habitantes.

33 «...En el orden jurídico la vinculación y conexión sistemática del territorio con los fenómenos ambientales ha sido producto de una lenta evolución histórica y, a través de una serie sucesiva de aproximaciones parciales, producto de experiencias y técnicas surgidas en ámbitos diversos.

Pues bien. De esta desconexión entre los problemas del medio ambiente y los del territorio arranca la confusión extraordinaria que en torno al concepto jurídico del ambiente hoy existe, además de determinar también, en un principio, una valoración del territorio exclusivamente desde una perspectiva de política económica y en función de su desarrollo programado, al objeto de conseguir una adecuada localización de las actividades económicas y de los asentamientos humanos.». María del Rosario Alonso IbáÑez, Los Espacios Culturales en la Ordenación Urbanística. Marcial Pons Ediciones, Madrid, 1994, pág.19.

${ }^{34}$ Sobre el tema nos hemos referido en el trabajo «Los Problemas de la Protección Patrimonial en la Regulación de la Reforma del Estado», publicado en la Revista Anales de la Facultad de Ciencias Jurídicas y Sociales, de la Universidad Nacional de La Plata, Tomo XXXII, pag. 91 y ss.

35 «...La arquitectura, aparte de unos pocos libros, es la única forma de historia posible. En algunos casos ni siquiera se conserva la literatura y queda la arquitectura sola como testigo mudo pero elocuente: un edificio vale más que mil palabras porque es una imagen dura que dura. Se puede pensar en el antiguo Egipto, en Persia y aun en esa China en que el primer emperador destruyó «todos los libros» para borrar el pasado, pero donde la única construcción humana visible desde el punto de vista de los dioses, la Gran Muralla, no es la labor de ingenieros militares sino la obra imperecedera de Arquitectos Anónimos...». Guillermo CABRERA INFANTE. El Libro de las Ciudades. Ed. Alfaguara, Madrid, 1999, pág.15.

${ }^{36}$ Entre 1947 y 1960, más de un millón de personas se trasladaba desde el interior del país hacia la región metropolitanita, acentuando el desequilibrio con las provincias, cuyas economías regionales se verían duramente quebrantadas. El Gran Buenos Aires, que en 1918 tenía la mitad de la superficie de la ciudad, en 1964 era ocho veces más grande, ya que incorporaba anualmente 14.000 hectáreas de tierras de cultivo al voraz crecimiento de la mancha urbana. Mientras el 93\% de las viviendas de la ciudad tenían cubiertos los servicios de aguas corrientes a mediados de los sesenta, solamente el 14\% de los distritos del oeste del conurbano bonaerense (Matanza, Merlo, Morón) contaba con red de agua. 


\section{A MODO DE COROLARIO}

El planeamiento urbano local debe superar la histórica y restringida idea del «ornato y la salubridad», para constituir una expresión que refleje una forma sistematizada de actuación sobre el territorio, contemplando criterios de participación, pautas ambientales, la preservación del patrimonio cultural y las distintas entidades territoriales a las que va dirigida.

Esperamos con estas sinópticas consideraciones, haber contribuido con los objetivos de esta prestigiosa publicación, y el interés del Profesor Enrique Orduña Rebollo, que generosamente nos convocó.

Nos hemos abocado a la cuestión en el libro Derecho Urbanístico, Volumen III, Área Metropolitana, editorial La Ley, año 2002. 